Lexis Vol. XLV (2) 2021: 691-727

\title{
Los ejemplos en las artes de la lengua quechua (siglos XVI-XVIII): primera aproximación"
}

\author{
Ana Segovia Gordillo \\ https://orcid.org/0000-0002-0880-6581 \\ Universidad Rey Juan Carlos (Madrid) \\ ana.segovia@urjc.es
}

\section{RESUMEN}

El presente artículo explora la parte ejemplificativa de las gramáticas de la lengua quechua compuestas entre 1560 y 1753: un total de nueve artes misioneras. Analizamos el marcado de los ejemplos, su temática, su función y su procedencia. Así, por un lado, sacamos a la luz las vinculaciones que existen entre las gramáticas de esta tradición; y, por otro, conectamos los ejemplos usados por los misioneros con los fines didácticos y evangelizadores de estos textos gramaticales. Para ello, nos centramos en el análisis de los capítulos relacionados con el nombre.

Palabras clave: lingüística misionera, quechua, ejemplos, gramática

Este trabajo forma parte de las investigaciones realizadas por el grupo de investigación de alto rendimiento Lingüística y Nuevos Medios (LIyNMEDIA) de la Universidad Rey Juan Carlos. Agradezco las observaciones y los comentarios que han hecho a este estudio los evaluadores de la revista. 
Examples in The Arts of The Quechua Language (16th-18th Centuries): A First Approach

\section{Abstract}

This article explores the examples of the Quechua grammars composed between 1560 and 1753: a total of nine missionary arts. It analyses the marking of the examples, their topics, their function and their origin so that, on the one hand, it brings to light the links that exist between the grammars of this tradition and, on the other hand, it connects the examples used by the missionaries with the didactic and evangelizing purposes of these grammatical texts. To this end, this paper focuses on the analysis of the chapters related to nouns.

Keywords: missionary linguistics, Quechua, examples, grammar

\section{INTRODUCCIÓN}

La lingüística misionera se centra en el estudio de la producción que realizaron los religiosos como fruto de su encuentro con las lenguas y las culturas indígenas de América, Asia y África; así pues, la producción misionera se desarrolló en unas amplias coordenadas espaciotemporales y tuvo en cuenta una gran diversidad de lenguas ${ }^{1}$. Con todo, a continuación, nos centramos en los trabajos lingüísticos originados en la América española. Estas obras son excelentes fuentes para conocer la etnografía de los pueblos americanos, ya que bajo los vocabularios y las gramáticas se esconden valiosas informaciones sobre la cultura e historia de los pueblos prehispánicos. Además, las artes y los diccionarios que se gestaron en el Nuevo Mundo son el resultado de la puesta en práctica de una incipiente lingüística aplicada, por lo que contienen informaciones relacionadas con la enseñanza y el aprendizaje de lenguas (metodología empleada, actitudes ante los problemas de traducción, etc.),

\footnotetext{
1 Para conocer con más detalle las áreas lingüísticas que abarcaron los misioneros españoles, véase el estudio de Acevedo López y Esparza Torres (2020).
} 
así como con la política lingüística adoptada por sus autores ${ }^{2}$. Al mismo tiempo, no hay que olvidar que las gramáticas y los vocabularios son de gran interés para la lingüística descriptiva, pues se revelan como valiosos documentos para el estudio tipológico o diacrónico de las lenguas de América. Finalmente, los vocabularios y las gramáticas que compusieron los clérigos en América son de gran valor para los historiadores de la lingüística, pues el estudio de las obras que compusieron los misioneros en suelo americano arroja luz sobre el pensamiento lingüístico de la etapa colonial y, de este modo, contribuye al conocimiento de la historia de la lingüística. Así, cobra fuerza la idea de que "a satisfactory history of linguistics cannot be written before the impressive contribution of missionaries is recognized" (Hovdhaugen 1996: 7).

Se ha reconocido, en estas primeras décadas del siglo XXI, una auténtica eclosión en los estudios sobre lingüística misionera. Esta nueva parcela de la historiografía de la lingüística se ha venido estudiando desde diferentes perspectivas, de forma que las investigaciones pueden privilegiar los aspectos fonéticos y ortográficos (Zwartjes y Altman 2005), las cuestiones morfosintácticas (Zwatjes, James y Ridruejo 2007), la materia lexicográfica (Zwartjes, Arzápalo Marín y Smith-Stark 2009) o las labores de traducción (Zwartjes, Zimmermann y Schrader-Kniffki 2014). Esta disciplina también se ha ocupado de la edición crítica de gramáticas o vocabularios (la colección Lingüística misionera de Iberoamericana/Vervuert y las reproducciones facsímiles de la Agencia Española de Cooperación Internacional) o del estudio de las fuentes y las repercusiones de esta producción en el pensamiento lingüístico español (Zwartjes 2000). Otras investigaciones se han centrado en el agente en la producción lingüística misionera (Esparza Torres 2015, 2017) o han puesto de relieve que el estudio de los elementos paratextuales de estas obras conlleva una comprensión más profunda de las mismas (Esparza Torres 2005, Cancino Cabello 2017, Segovia Gordillo

\footnotetext{
2 Puede consultarse Cerrón-Palomino (2010) para conocer la situación del contacto lingüístico inicial entre el castellano y el quechua tras la conquista.
} 
2020a). Igualmente, en otros trabajos se han ido perfilando los presupuestos teóricos de la historiografía de la lingüística misionera (Zimmermann 2004, Hernández 2013)3. Sin embargo, el análisis de los ejemplos contenidos en las obras gramaticales misioneras es una cuestión poco trabajada hasta el momento.

En el marco de la gramaticografía española, varios estudios se centran en el rastreo de fuentes y autoridades literarias en los ejemplos contenidos en las gramáticas (Lliteras 2001, Niederehe 1994 o Quijada van den Berghe 2011, entre otros). Otros, como Calero Vaquera (2010) y Zamorano Aguilar (2013), abordan el estudio de los ejemplos desde el punto de vista de la glotopolítica. Por su parte, Escudero Paniagua (2019) afronta el estudio de la ejemplificación en gramáticas del siglo XVIII y la primera mitad del XIX, mientras que Esteba Ramos analiza los ejemplos en las gramáticas del Siglo de Oro destinadas a la enseñanza del castellano como lengua extranjera y concluye lo siguiente:

Los ejemplos de cualquier tipo de gramática sirven para ilustrar los aspectos teóricos a los que dan cabida estas obras. Por este motivo, básicamente contribuyen a que el lector interesado en el aprendizaje o la reflexión sobre la lengua acceda de manera más diáfana a las ideas lingüísticas. Las gramáticas de lenguas extranjeras en concreto, por lo general, recurren más a este mecanismo pedagógico, ya que en ocasiones simplifica bastante la tarea tanto del autor como del lector (Esteba Ramos 2006: 685).

De hecho, Chevillard, Colombat, Fournier, Guillaume y Lallot (2007) comienzan su investigación afirmando que los ejemplos son un componente necesario de toda gramática y Marchello-Nizia y Petiot mantienen que "l'usage que font des exemples les grammairiens et les linguistes peut nous éclairer sur leur pratique et sur le rôle que jouent leurs ouvrages" (1977: 84). A la hora de definir los ejemplos, partimos de los presupuestos de Chevillard y otros:

\footnotetext{
3 Para conocer los estudios publicados en este campo, así como las investigaciones pendientes, puede consultarse Zwartjes (2012). En Regúnaga y Zwartjes (2020) se encontrará una revisión de los congresos celebrados y las publicaciones a que han dado lugar.
} 
"Nous sommes donc convenus d'appeler exemple, dans un texte grammatical, tout objet linguistique, quelle que soit sa structure, issu de la langue objet: tout fragment de la langue objet inséré dans le discours grammatical" (2007: 6).

Como mencionábamos arriba, pocos investigadores se han acercado al estudio de los ejemplos de las artes misioneras. Rodríguez-Alcalá en 2007 estudia esta cuestión en las gramáticas jesuíticas del guaraní (Aragona hacia 1629, Montoya 1640 y Restivo 1724) y afirma que los jesuitas hicieron un arduo trabajo de campo en colaboración con los indígenas para constituir su corpus de ejemplos. De acuerdo con dicho estudio, no se trata de citas literarias: los misioneros invocan la autoridad del indio a través de ejemplos tomados de la oralidad. En este sentido, la investigadora entiende la oralidad no solo como punto de partida, sino también como punto de llegada de estas gramáticas, pues su propósito es no cometer errores al hablar, entender y ser entendido; por ello, la selección de los ejemplos responde a necesidades de la comunicación oral. Posteriormente, en 2008, Rodríguez-Alcalá y Horta Nunes evalúan el trabajo de estandarización realizado por los jesuitas en sus descripciones del tupí y del guaraní, prestando especial atención a los ejemplos contenidos en las obras que analizan, y concluyen que los procedimientos de ejemplificación no pueden disociarse de las condiciones sociales y políticas en las que tuvo lugar este trabajo gramatical.

\footnotetext{
4 El corpus de Rodríguez-Alcalá es el siguiente: Aragona, Alonso de [hacia 1629] 1979. "Breve introducción para aprender la lengua guaraní”. En Amerindia, 4, 23-61 (ms. redactado hacia 1629, edición, presentación y notas de Bartomeu Melià); Ruiz de Montoya, Antonio [1640] 1993. Arte de la lengva gvaraní. Asunción: CEPAG [Centro de Estudios Paraguayos «Antonio Guasch»] (edición facsimilar con introducción y notas por Bartolomeu Melià); y Restivo, Paulo [1724] 1892. Linguae guarani grammatica hispanica a R. P. jesuita Paulo Restivo, secundum libros Antonii Ruiz de Montoya, Simonis Bandini aliorumque, adjecto particularum lexico anno MDCCXXIV in civitate Sanctae Mariae Majoris, edita et "Arte de la lengua Guarani " inscripta, sub auspiciis et impensis illustrissimi Domini Petri, principis Saxo-Coburgensis Gothensis, ex unico quod in Europa noscitur ejusdem serenissimi principis exemplari redimpressa, necnon praefatione notisque instructa opera et studiis Christiani Frederici Seybold. Stuttgart: G. Kohlhammer.
} 
Por su parte, Cuevas Alonso (2011) se centra en las gramáticas filipinas y analiza la tipología, las funciones y el marcado de los ejemplos en estas gramáticas. En su propuesta de clasificación, este investigador distingue la organización interna de los ejemplos (simples o complejos), el carácter lingüístico de los mismos (si muestran cuestiones fónicas, morfosintácticas o léxicas) y la clasificación temática (verdades de la fe, vida cotidiana y la vida del misionero, carácter social-aculturador o ejemplos neutros). Por otro lado, Molina Landeros (2016) analiza los ejemplos de las gramáticas jesuíticas del noroeste novohispano (siglos XVII-XVIII). De acuerdo con esta autora, "el repertorio de ejemplos forma parte del discurso gramatical, por mostrar de forma directa lo enunciado en la explicación; es decir, es donde el metadiscurso se concretiza” (2016: 158). Tras su análisis, esta investigadora ofrece una taxonomía de dichos ejemplos, los cuales están divididos en mensajes literales de adoctrinamiento, e inventos de los misioneros con contenido religioso o relacionados con cuestiones de la vida cotidiana.

\section{CORPUS, HIPÓTESIS DE PARTIDA Y METODOLOGÍA}

Vistas las vías de investigación abiertas sobre el tratamiento de los ejemplos en las artes misioneras, en este trabajo queremos presentar una primera aproximación a la parte ejemplificativa de las artes gramaticales de la lengua quechua. Nuestro corpus de estudio comprende lo que Mannheim (1991) y Calvo Pérez (2004) denominan el "Siglo de Oro quechua", es decir, el "rico período gramatical y lexicográfico que va desde 1560, fecha de la primera gramática y vocabulario publicados, hasta 1648 en que se extingue aquella fiebre generadora de textos técnicogramaticales" (Calvo Pérez 2004: 201). Además, hemos querido considerar otras dos gramáticas de bien avanzado el siglo XVII y una del siglo XVIII, época en la que se reduce considerablemente el número de estudios sobre el quechua (véase Dedenbach-Salazar Sáez 2008). Así, para la elaboración de esta investigación, se ha trabajado con las siguientes gramáticas: la Grammatica o arte de la lengua general 
de los Indios delos Reynos del Peru (1560) de Domingo de Santo Tomás (1499-1570); el Arte, y vocabvlario enla lengva general del Perv (1586), obra atribuida recientemente a Blas Valera (hacia 15451597) en calidad de director del equipo encargado de su elaboración (Cárdenas Bunsen 2014); la Gramatica y arte nveva dela lengva general de todo el Peru (1607) de Diego González Holguín (15601618); el Arte dela lengva quechva general delos Yndios de este Reyno del Piru (1616) de Alonso de Huerta (1562-1640); el Arte de la lengva quichua (1619) de Diego de Torres Rubio (1547-1638); el Arte de la lengva general de los indios del Perv (1648) de Juan Roxo Mexía y Ocón (1602-1648); el Arte de la lengva general de los indios del Perv ([1690] 1939) de Juan de Aguilar; el Arte de la lengva general del Ynga llamada Qquechbua (1691) de Esteban Sancho de Melgar; y la Breve instruccion, o arte para entender la lengua comun de los Indios, segun se babla en la Provincia de Quito $(1753)^{5}$. Analizaremos, por tanto, nueve gramáticas que se enmarcan cronológicamente entre 1560 y 1753.

Nuestro objetivo es proponer otros enfoques a la hora de abordar el estudio de la lingüística misionera española y explorar los ejemplos contenidos en las gramáticas antes mencionadas. Partimos de una doble hipótesis, según la cual, por un lado, el análisis de los ejemplos nos permitirá comprender mejor la labor de los misioneros lingüistas del área andina; es decir, podremos progresar en la comprensión de las finalidades de este tipo de textos, pues, como afirma Molina Landeros, "los verbigracias de estos compendios no solo sirvieron como apoyo para la inserción de información gramatical, sino también como modelos de lengua en un contexto cotidiano y catequístico" (2016: 163). Por otro lado, el examen de la parte ejemplificativa podrá poner de manifiesto las posibles redes de influencias, ya que, como explica Esteba Ramos, los ejemplos se revelan como una "herramienta útil para la determinación de las

\footnotetext{
Con las excepciones de Huerta y Aguilar, en la Biblioteca Virtual de la Filología Española (Alvar Ezquerra 2020) se pueden encontrar ejemplares digitalizados de estos textos.
} 
dependencias o copias" (2006: 686), esto es, el hecho de detectar coincidencias significativas entre los ejemplos empleados podría considerarse una prueba del diálogo entre gramáticas.

En relación con lo anterior, es pertinente resaltar que las investigaciones precedentes han señalado que algunas obras gramaticales actuaron como focos e iluminaron a otros gramáticos de la lengua quechua. En este sentido, el Arte, y vocabvlario de 1586 representa la llamada "escuela de Lima", donde se toman acuerdos generales sobre el quechua (como el uso de las cinco vocales o el reconocimiento del plural inclusivo y exclusivo), que serán retomados por los gramáticos posteriores (Calvo Pérez 1997). En segundo lugar, se encuentra la Gramatica y arte nveva de Diego González Holguín, resultado de las resoluciones tomadas en la "escuela de Juli", un auténtico centro de estudio de lenguas (Calvo Pérez 1997, Segovia Gordillo 2016). Así, por ejemplo, Calvo Pérez (2004) subraya la vigencia de las explicaciones de González Holguín sobre las perífrasis verbales ${ }^{6}$ y Segovia Gordillo (2020b) advierte coincidencias entre González Holguín y Torres Rubio en el tratamiento de las interjecciones y las conjunciones. En tercer lugar, consideramos también el Arte de la lengua Quichua general de Indios del Peru, ya que Segovia Gordillo (2020b) mantiene que el tratamiento que Aguilar realiza de las conjunciones parte de Roxo Mexía, pues aquel llega incluso a introducir los errores de este. El análisis de los ejemplos que realizamos aquí tal vez pueda confirmar estas dependencias y mostrar otras nuevas.

Finalmente, en relación con la metodología empleada, el estudio que se presenta se llevó a cabo conforme al siguiente plan de trabajo: en primer lugar, se fijó el corpus de ejemplos que se estudiaría. Se decidió que en este acercamiento inicial no se presentaría un trabajo exhaustivo, sino más bien panorámico, dado el número de gramáticas seleccionadas. Así pues, se resolvió comparar los ejemplos

\footnotetext{
6 “Después de DGH [Diego González Holguín], los autores del Siglo de Oro quechua (hasta 1648) se limitan a copiar de él las estructuras perifrásticas del quechua" (Calvo Pérez 2004: 96).
} 
contenidos en los capítulos dedicados al nombre, primera parte de la oración estudiada por los misioneros lingüistas. En segundo lugar, se llevó a cabo una atenta lectura de los capítulos seleccionados prestando especial atención a la parte ejemplificativa. Con ello pudimos analizar cuestiones relacionadas con las lenguas implicadas, la marcación de los ejemplos, la función que estos cumplen desde el punto de vista lingüístico o la primacía del criterio del uso frente a la norma. En tercer y último lugar, se procedió al vaciado de los ejemplos. Todos ellos (un total de 626) se analizaron en un documento Excel en el que se reflejó la siguiente información por columnas: autor de la gramática y año, ejemplo en quechua, traducción en español y ámbito temático al que se puede circunscribir. Gracias a la creación de filtros en el documento Excel, se pudo estudiar los grupos temáticos establecidos y la procedencia de los ejemplos. Para ello, se ordenó alfabéticamente la columna con los ejemplos en castellano, de forma que se podían apreciar las coincidencias entre gramáticas y se filtraron manualmente los grupos temáticos creados para observar la cantidad de ejemplos destinados a cada uno de ellos.

\section{LENGUAS IMPLICADAS Y MARCADO DE LOS EJEMPLOS}

No hay que olvidar que las gramáticas examinadas (así como los vocabularios) surgieron en la época colonial como "un apoyo para el aprendizaje y el uso de las lenguas vernáculas por parte, principalmente, de los sacerdotes” (Ezcurra Rivero y Bendezú-Araujo 2017: 125). Los misioneros entienden que las artes gramaticales (y los diccionarios bilingües) son el medio más adecuado para lograr su propósito final - la evangelización de los indígenas- y esta motivación queda reflejada en sus prólogos (Segovia Gordillo 2020a). En las gramáticas, el castellano se convierte en la herramienta apropiada para describir la lengua quechua y esta elección no solo tiene que ver con las necesidades didácticas de los alumnos (que podían ver en el latín un obstáculo), sino que, como apunta Zwartjes, también se debe a que, en las artes misioneras, el español funcionaba como puente entre el latín —lengua que soportaba la teoría grama- 
tical del momento- y la lengua amerindia que se quería describir (2007: 818). Así, en los textos gramaticales estudiados, entran en juego el español, la lengua materna de los autores; el latín; y, en menor medida, el hebreo ${ }^{7}$ (esto es, los idiomas que los religiosos habían estudiado). Por todo ello, en la parte ejemplificativa de las gramáticas analizadas, las expresiones en quechua se acompañan de sus equivalencias en español y, en ocasiones, en latín.

El (man) significa 'movimiento' y ayúntase siempre con verbo que significa 'movimiento' y significa lo que dezimos en romance 'de' con movimiento y en latín (ex) o (abs), como diziendo 'vino del Señor’ diremos (yayánc mánta xamúrca) (Santo Tomás 1560: 7r) ${ }^{8}$.

Y aunque algunos dizen que en iglesia puncu se suple el genitivo, mas yo siento y es más conforme a arte que es verdadera composición de dos nombres en uno adjetivados, porque todos los genitivos en esta lengua como en la hebrea y los nombres de la materia delas cosas artificiales como cullqui aquilla 'vaso de plata' se convierten en nombres adjetivados, como los hay en el latín, domesticus de genitivo domus y argenteus, de la materia de la plata de que se haze algo. Y assí acá del genitivo buaci se haze un adjetivo que dize 'puerta doméstica'; iglesia puncu, ecclesiastica porta, 'puerta de la iglesia'; curi buallca, aurea catena 'cadena de oro' (González Holguín 1607: 4r).

\footnotetext{
7 En su obra gramatical, González Holguín compara en una ocasión el quechua con el hebreo. También introduce términos metalingüísticos como el sustantivo raíz o el verbo afixarse (1607: 4r). Lliteras y García-Jalón mantienen que “en la formación humanística de estos gramáticos y lexicógrafos, es evidente que los conocimientos filológicos de origen grecolatino se complementan con la tradición hebraica renacentista, pues los misioneros aplicaron unas y otras fuentes a la descripción de las lenguas del Nuevo Mundo. El hebraísmo, en fin, cruza el Atlántico al mismo tiempo que avanza por las universidades más prestigiosas del Viejo Continente" (2006: 38). En cualquier caso, la presencia de la tradición gramatical hebrea en las gramáticas misioneras es una materia aún poco explorada.

8 En las citas de las gramáticas misioneras, hemos usado los "Criterios de edición de documentos hispánicos” propuestos por la Red Internacional CHARTA. Siguiendo sus directrices, los fragmentos en otra lengua (quechua o latín) se marcan en cursiva (aun cuando no aparece así en el texto original). Además, se añaden comillas simples para señalar las traducciones o equivalencias. Mantenemos, sin embargo, la transcripción en los títulos de las obras.
} 
Los ejemplos más numerosos son aquellos en los que la expresión en la lengua andina antecede a la traducción, como en "El genitivo, si el nombre se acabare en vocal, tiene una $p$, como yayap, 'del padre'. Si el nombre se acabare en consonante o en dos vocales, tiene pa, como yahuarpa, 'de la sangre'; moscoypa, 'del suelo'” (Torres Rubio 1619: 1r). No obstante, también encontramos casos en los que el gramático prefiere poner primero la traducción y seguidamente la expresión en quechua:

El acusativo [tiene] ta y man y esta última partícula se debe usar cuando es de movimiento, y no de ta, v. g. 'voy a fuera' canchaman rini. Y no por esto excluyo que se deba también usar cuando no es para movimiento principalmente cuando el verbo rige dos casos, uno de persona y otro de cosa, porque entonces el man se pone con el caso de persona y el ta con el caso de cosa, v. g. 'yo te pido plata' culquita canman mañani, 'yo te doy oro' curitacam man cuni (Autor desconocido 1753: 2v).

Como explican Chevillard y otros, "l'insertion d'un exemple dans le discours du grammairien pose un problème auquel il faut apporter une solution technique” (2007: 8). Así pues, con respecto al marcado de los ejemplos, en las gramáticas analizadas encontramos distintas tendencias observables en los textos originales: Huerta, Roxo Mexía, Sancho de Melgar y el autor de la Breve instruccion resaltan la expresión en quechua en cursiva; González Holguín, en cambio, prefiere escribir en itálicas la traducción al español; Santo Tomás y el Arte, y vocabulario enmarcan la expresión en quechua entre paréntesis; los misioneros también usan la abreviatura del latinismo verbi gratia “v. g." (Santo Tomás, Roxo Mexía, Breve instruccion) o el ut latino (Torres Rubio); o bien marcan las expresiones en quechua a través de verbos de lengua (Santo Tomás, González Holguín, Torres Rubio); finalmente, para anunciar los paradigmas, aparece explícitamente la palabra "exemplo" (Santo Tomás, el Arte, y vocabvlario, González Holguín, Roxo Mexía y Aguilar). Por lo tanto, nos encontramos con dos posibilidades: el marcado tipográfico (paréntesis y cambio de fuente) y, utilizando la terminología propuesta por Chevillard y otros (2007), el “marcado 
robusto"; en este último, el ejemplo se señala a través de términos metalingüísticos o secuencias introductorias más complejas formadas por un verbo de lengua. Ahora bien, no se trata de decisiones sistemáticas: en ocasiones, el ejemplo no se marca, pues como apuntan Chevillard y otros, "dans le cas des grammaires bilingues, cette différence peut être déjà suffisamment sensible dans la différence des codes linguistiques" (2007: 8).

En relación con los paradigmas, junto con las denominaciones casuales clásicas, se organizan las palabras quechuas con las partículas que indican las funciones casuales y su traducción al español. Se trata, por tanto, de una triple columna que facilita el aprendizaje contrastivo.

Exemplo delos nombres acabados en dos vocales

Nomi. punchan 'el día'

Gen. punchaupa 'del día'

Dati. punchaupac 'para el día'

Acu. punchauta

punchauman 'al día'

Vocati. punchau 'o día'

Ablati. punchaupi 'en el día'

punchaumanta 'del día'

punchaubuan 'con el día' (Autor desconocido 1586: 3r-3v).

Sancho de Melgar y la Breve instruccion representan una excepción a esta forma de proceder: el primero porque no propone la traducción al español, sino al latín (muestra de la orientación traductológica de su gramática):
N. Churi
Filius
G. Churi-p
Filij
D. Churi-pacc
Filio
Ac. Churi-cta
Filium
vel Churi-man
In Filium
vel Churi-raycu
Propter Filium 
V. Churivel aa churi, vel churi-ya

Ab. Churi-pi

vel Churi-unan vel Churi-manta

O Fili

In Filio

Cum Filio

$e$, vel ex, vel de Filio (Sancho de Melgar 1691: 1r).

Y el segundo porque cambia el orden y prefiere dar primero la traducción al español y después la expresión quechua.
N. 'El día'
Puncha
G. 'Del día'
Punchapac
D. 'Para el día'
Punchapac
Ac. 'Al o contra el día'
Punchaman vel punchata
V. 'O día'
Puncha

Ab. 'En, con, por, del día' Punchapa, punchabuam, punchamanta (Autor desconocido 1753: 3v)

\section{FunCIÓN DE LOS EJEMPLOS}

Marchello-Nizia y Petiot explican que el lugar de los ejemplos varía según el tipo de obras (1977: 85). En las gramáticas de la lengua quechua, el ejemplo sigue la declaración de la regla o definición:

El número plural se constituye o compone del número singular añadida esta dicción (cóna). V. g. Dezimos (yayanc) que quiere dezir 'señor' añadiendo (cóna) dirá (yayánccóna) que quiere dezir 'señores' y assí diremos (yayánccóna) 'los señores', (guarmecóna) 'las mugeres' (Santo Tomás 1560: 4r).

Los números son dos: singular y plural; el singular habla de uno, como runa 'persona'; el plural, de muchos y házese con esta partícula cuna añadida al singular, como runa cuna 'personas', churi cuna 'hijos' (Huerta 1616: 2r).

Se hallan también en esta lengua los dos números, singular y plural. Hacen plural añadiendo al singular esta partícula cuna, v. g. yutu 'la 
perdiz', yutucuna 'las perdizes' y en los demás casos se interpone entre el nombre y la partícula que denota el dicho caso, v. g. yutu cunapac, 'de las o para las perdices' (Autor desconocido 1753: 3r).

Como puede verse en las citas anteriores sobre la regla de formación del plural, el ejemplo adquiere aquí un valor probatorio y las reglas son formuladas en función del uso, es decir, de los ejemplos que los misioneros recogen. En otras ocasiones, los ejemplos muestran las excepciones a las reglas propuestas.

Es de notar cerca d'esta regla del plural que esta dicción (cóna) haze plural en los nombres que significan cosas animadas o que viven como (cári) que significa 'varón' añadiendo (cóna) diziendo (caricóna) dize 'varones'. Ítem (guarme) significa 'mujer' añadiendo (cóna) como (guarmecóna) dize 'mujeres’ y assí de todos los demás. Pero a los nombres que significan cosas inanimadas que no viven no lo suelen añadir. V. g. (pirca) que significa 'pared' no acostumbran en esta lengua dezir en el plural (pircacóna) sino que dan a entender pluralidad o muchedumbre en los tales nombres con un adjetivo que le ayuntan absoluto o numeral, como si quieren dezir 'muchas paredes' añaden aquel adjetivo (áchica) que significa 'muchas' y assí dizen (áchicápirca) 'muchas paredes' y si quieren dezir pocas añaden otro adjetivo que es (pixin) o (áxlla) que significa pocas, como diziendo (áxlla pirca) o (pixin pirca) que quiere dezir pocas paredes o añaden (guáquin) que significa 'algunas', como diziendo (guáquin pírca) 'algunas paredes' o añaden un nombre numeral declarando el número dos o tres o cuatro y assí en las demás diziendo (yscáy pírca) que significa 'dos paredes', (quinçapírca) que significa tres paredes $o$ las que quisieren señalar. Verdad es que en todas generalmente se podría añadir aquella dicción (cóna) que en la regla dixe que significava pluralidad y començándose a usar lo entenderían todos, pero como digo no lo acostumbran (Santo Tomás 1560: 4r-4v).

A través de los ejemplos, los misioneros también pueden señalar construcciones incorrectas. Así, cuando González Holguín explica cómo se juntan sustantivos y adjetivos en quechua (lo que este gramático denomina “declinación adjetivada”), propone el ejemplo ñucñu taqui ‘suave música o canto', ñucñu taquip 'del canto suave', ñucñu taquipac 'para el canto suave', etc., y explica lo siguiente: 
Discíp. ¿En qué se diferencia esta declinación de las passadas? Mae. No en la terminación, sino en sola esta junta de adjetivo y sustantivo, que tiene mucho que notar. Lo primero que en esta lengua siempre el adjetivo se antepone al substantivo como aquí y no se puede dezir tanqui ñucñu. [...] 2. Nota aquí que el adjetivo no se declina acá como en latín, porque los casos no se ponen más que una vez al postrero nombre (González Holguín 1607: 3v).

Por último, los ejemplos en las gramáticas del quechua dan cuenta de la variación lingüística, pues la falta de un canon establecido obliga a aducir variantes. A este respecto, podemos mencionar los paradigmas de la “declinación genitivada”, que incluye González Holguín. De acuerdo con este gramático, esta construcción "tiene por nominativo el genitivo de los nombres y sobre él recibe otro genitivo y los demás casos” (1607: 6v). Calvo Pérez denomina este proceso en el cual un genitivo es tomado como nominativo y declinado otra vez "sobredeclinación” (1993: 335-339); así, de wasi 'casa', tendremos wasi- $q$ 'de la casa/ lo de la casa', wasiq-pa 'de lo de la casa', wasiq-manta 'desde lo de la casa', wasiq-wan 'con lo de la casa', wasiq-rayku 'a causa de lo de la casa', etc. Pues bien, González Holguín afirma que "para hazer esta significación 'lo que es de alguno o lo que es suyo de aquel nombre que possee', toman el genitivo y declínanlo otra vez y esto no de una, sino de muchas maneras galanas" (1607: 6v). Concretamente, explica tres formas diferentes: runap o runallap 'lo que es del hombre', runapnin o runallanin 'lo que es del hombre', y apup o apupchaynin 'lo que es del juez o señor’. Como explica Ridruejo,

la codificación implica algo más que la mera representación gráfica del discurso. Exige también la selección de una determinada variedad, cuando hay diferencias dialectales o, incluso, en alguna de las llamadas lenguas generales, diastráticas. La labor del gramático puede haber supuesto, entonces, la elevación de un determinado dialecto, geográfico o social, en detrimento de otros (2014: 622).

La gramática de González Holguín ofrece una descripción del quechua hablado en la región del Cuzco, pero también muestra cierta variedad sociocultural, como se puede intuir de la siguiente cita: 
Discíp. ¿De cuántas maneras se forman estos possesivos?, ¿de tres como está aquí o de dos? Maest. En el Cuzco y entre buenos lenguas se usan todas tres; y la tercera, ninñiy, no la usan todos, sino los muy curiosos por galanía. Y nótese su significación, que añade esse o aquel, que aun en romance son dos possessivos, 'mi padre' o 'esse mi padre' o 'aquel mi padre' o 'este mi padre', que todo lo dize el (nin) y responde al del latín is, ea, id. Y si quiera para entender a los que hablan assí se deve poner en el arte, pues es cosa usada (González Holguín 1607: 15v)9.

En este punto es necesario insistir en que el uso tiene un papel predominante en la tradición misionera. Los misioneros rompen con la tradición latina, pues para ellos la gramática no es el arte de hablar y escribir correctamente de acuerdo con el uso de los autores eruditos, como la definía Nebrija (hacia 1488) ${ }^{10}$, por ejemplo. Los lingüistas misioneros considerados en este trabajo descartan el criterio de la auctoritas, pues las lenguas que describen no cuentan con una tradición literaria previa, y se valen de los testimonios orales de los indios para confeccionar sus gramáticas, que tienen, por tanto, un carácter eminentemente descriptivo. Santo Tomás incide en la idea de que el uso de los “inventores” del quechua será lo que le guíe en su descripción gramatical:

Pero la principal razón en esto de los nombres y hablas es el uso, porque assí se usa y lo usaron los que primero hablaron la lengua y usan bien d'ella: porque el hablar d'esta manera y no de aquella depende de la voluntad de los primeros inventores d'ella, y que primero la usaron hablar; y lo mismo se dize de todas las demás maneras de hablar, verbos, tiempos, o nombres que hay en esta lengua de más o de menos, que no los hay o los hay en la latina o española. Porque en cada lengua y términos d'ella, lo principal consiste en el uso: conviene saber, porque assí lo usan los que bien la hablan (1560: 4v).

\footnotetext{
9 Así, para Mannheim, el arte de González Holguín “no solamente trata de la gramática en el sentido estricto de la palabra, sino también de la retórica (hoy en día la "pragmática”), es decir, de las maneras en que se usa el idioma como una herramienta social para expresar, persuadir, insultar, etc., hasta para comentar el humor" (2002: 212).

10 "¿Qué cosa es Grammatica? Sciencia de bien hablar \& bien escriuir, cogida del uso \& autoridad delos muy enseñados varones” (Nebrija 1996 [c. 1488]: 94).
} 
De igual manera, Sancho de Melgar se basa exclusivamente en el testimonio de los indios: "Y aunque este uso y el del número antecedente parecen bárbaros, advierto que son muy practicados y la mayor elegancia en esta lengua (como en las demás) será hablar como los naturales sin querer, como algunos han intentado, reformar el idioma" (Sancho de Melgar 1691: 4r). Asimismo, González Holguín explica en su prólogo que los indígenas colaboraron en la composición de sus obras lingüísticas:

Habiendo, pues, yo juntado con alguna curiosidad por más de veinticinco años, todas las cosas curiosas, sustanciales y elegantes que he hallado en esta lengua, viéndolas primero puestas todas en uso, y repreguntando de nuevo a muchos indios grandes lenguas, y enterado en la práctica y uso de todo, porque salieron las cosas muchas, y tantas, que excedían el justo tamaño de arte, mas por ser todas cosas importantes para la perfecta inteligencia de la lengua no se podía dexar, tomé este acuerdo, que las repartí en cuatro libros (1607: “Al pío lector”).

\section{Clasificación temática}

En este epígrafe queremos abordar otra faceta de los ejemplos estudiados: aquella que no está en relación con las funciones lingüísticas, sino con la temática de los ejemplos elegidos por los misioneros. Para ello, tomando la traducción propuesta por los gramáticos, hemos clasificado los ejemplos analizados en distintos ámbitos designativos. En primer lugar, establecemos un gran centro de interés que tiene que ver con el ser humano desde una perspectiva amplia, que dividimos en varios grupos temáticos: morfología del ser humano (cabello, carrillos, ojos...), alimentación (agua, maçamora, frijoles...), vivienda y sus partes (adobes pequeños, casa, plato de plata, portezuela...), vestimenta y accesorios (entrambos antojo, cadena de oro, ambos zapatos...), oficios y relaciones sociales ( $\mathrm{mi}$ compañero en casa, los condiscípulos, la criada, el mayordomo, el portero...), aspectos relacionados con la muerte y la enfermedad (enemigo, enfermedad, muerte, sentenciado a muerte, el que murió 
a espada por sus pecados...) y relaciones de parentesco (bermano, bermana, hijo, hija, sobrino, tía... $)^{11}$. Otros grupos temáticos que hemos identificado son aquellos relacionados con la fauna (ave, carnero, culebra, perdiz...) o con la flora y el terrero (árbol, arboleda, camino llano, maizales, pedregal...). También distinguimos conjuntos temáticos relacionados con los astros (luna, sol) o con los números, así como con expresiones para delimitar el tiempo y el espacio (todos los días, un mes entero, un año entero, acullá, allí, aquí, allá en el campo o desierto, allá en la iglesia...). Las gramáticas también recogen abundantes ejemplos de contenido religioso sobre Dios (Dios os ve cuando pecáis, Dios que bizo cielos y tierra, amo a Dios...), los ángeles (el que es igual a un Ángel en puridad o castidad), Jesús (Jesucristo Dios, que es bijo de Dios, creo en Jesucristo el cual se hizo hombre por obra del Espiritu Santo) o el pecado (el que aborrece todo pecado, los hombres pecan).

Por otra parte, dado que hemos examinado los capítulos relacionados con el nombre y que la lengua quechua carece de género gramatical, los misioneros registran términos para distinguir el sexo de animales y personas (bembra, macho, mujer, varón). Además, hallamos ejemplos a los que podemos denominar "dialógicos", "por hablar en ellos diversos sujetos hablantes" (Chierichetti 2009: 114): ¿por cuántos días vas? / por un año, ¿en cuánto compraste? / en seis, ¿por cuánto vendes? /por tres, ¿por qué riñes? / porque eres perezoso... Igualmente distinguimos un número significativo de ejemplos que hemos considerado enunciados de la vida cotidiana: ando por el camino, bolverás por la plaça, el pan que me diste es frí, llama a Pedro el que vino ayer, quiero comer, téngote por hombre bueno, vendiéronle dos carneros como caballos, vengo del pueblo, voy al pueblo, sin mi se bizo esto, trae aquella fruta que te di a guardar... Finalmente, en las artes se documentan términos

11 Los misioneros se percataron de que las palabras que designan las relaciones de parentesco en quechua varían según el sexo del hablante, de manera que los hombres y las mujeres poseen dos sistemas diferentes. Para conocer en profundidad descripción del léxico del parentesco del quechua que reflejan las gramáticas de los siglos XVI y XVII consúltese Bendezú-Araujo (2012). 
relacionados con la cultura inca (coya, inca, Atabualpa, chinchaysuyos, provincia Chincha, Xaúxa) y quechuismos (curaca, chacra o chácaras, cuy, aillo, puma, llama). Sin duda, como afirma Ridruejo:

Y es que el contacto con los europeos supuso para los indígenas americanos y filipinos (lo mismo que para los europeos) la necesidad de ampliar su vocabulario para la mención de nuevas realidades, naturales, técnicas y también culturales. Los misioneros asumen en sus obras lingüísticas la incorporación del vocabulario europeo con especial atención a los conceptos ideológicos y religiosos del cristianismo que pretender introducir. De esta manera, en los diccionarios, pero también en ocasiones, en las gramáticas se incorporan préstamos, voces latinas o hispánicas que se introducen directamente, evitando la adaptación (2014: 623).

Precisamente, de las palabras castellanas que penetraron en el quechua, da cuenta Huerta en la siguiente cita:

Declinan y conjugan a su modo muchos nombres y verbos castellanos de que no tiene nombres ni verbos por no haver tenido noticia de las cosas que significan, como gracia, virtud, Espiritu Santo, Dios, confesar, perdonar. Y en los nombres que declinan de estos si están pluralizados no es necessario añadirles la partícula cuna, como virtudespa 'de las virtudes', Diosespa 'de los dioses' (1616: 2v).

De nuestro análisis se desprende que los ejemplos más numerosos son aquellos que se refieren a cuestiones religiosas (16\%), seguidos de los que hemos englobado dentro de la categoría de enunciados de la vida cotidiana (14\%).

\section{AnÁlisis CONTRAstivo de los EJEMPlos}

El abanico de ejemplos empleado en las gramáticas de la lengua quechua se configura como un corpus abierto ${ }^{12}$. Además, hemos encontrado ejemplos que se repiten en varios autores y otros que

\footnotetext{
12 A este respecto, como futura línea de investigación, sería necesario investigar sobre la posibilidad de que las doctrinas y los catecismos sirvieran como corpus en el caso de los ejemplos con contenido religioso.
} 
se convierten en "canónicos”. Para ilustrar estas ideas revisaremos los ejemplos coincidentes siguiendo el orden de aparición de las gramáticas.

Santo Tomás propone cári 'varón' como ejemplo de los nombres sustantivos y este es recuperado por el Arte, y vocabvlario (cari 'varón') y por Aguilar (ccari ‘el varón'). González Holguín recoge el paradigma de ccari ‘el varón’ como ejemplo de nombre sustantivo acabado en vocal y Roxo Mexía alude a ccari ‘el varón’ para explicar "el modo de suplir los géneros" (1648: 8r), es decir, la manera en la que la lengua quechua, al carecer de género, introduce información sobre el sexo de los seres racionales en este caso. Como ejemplos de nombres comunes, la gramática de 1560 presenta rúna 'hombre', término que vuelve a aparecer en el Arte, y vocabvlario (aunque sin aludir a los nombres comunes) y se presenta como paradigma desarrollado de los nombres acabados en vocal (runa 'el hombre'). También, Torres Rubio presenta el paradigma declinado de runa 'el hombre'; además, González Holguín recoge runa 'hombre' (pero lo hace cuando alude a la manera en que se unen el adjetivo con el sustantivo); y Huerta, al tratar el género, se refiere a runa, que traduce como 'persona, varón o muger'. Por otro lado, en Santo Tomás encontramos alli cári 'buen hombre' cuando explica el género de los nombres, ejemplo recuperado en el Arte, y vocabvlario (alli runa 'buen hombre') y en Torres Rubio (alliruna 'buen hombre') cuando este último explica que el adjetivo siempre se antepone al sustantivo. Santo Tomás también propone guárme 'mujer' y álli guárme 'buena mujer' para explicar la ausencia de género en quechua; este ejemplo será retomado en el Arte, y vocabvlario (buarmi 'hembra') y en Roxo Mexía (buarmi 'muger').

Como ejemplo de nombre primitivo, en el arte de 1560 se propone rúmi 'piedra' y, como veremos posteriormente, cuatro de los gramáticos posteriores usan la voz piedra para explicar los plurales formados por la repetición de nombres: Torres Rubio (varumiruni 'el pedregal y muchas piedras'), Roxo Mexía (rumirumi 'el pedregal' y no 'las piedras'), Aguilar (rumirumi 'el pedregal' y no 'las piedras') y Sancho de Melgar (rumi 'la piedra', rumirumi 
'pedregal'). A la hora de explicar los nombres "derivativos", Santo Tomás ofrece los términos tiana 'assiento' y tiani 'assentar', ejemplos recuperados por Huerta: "De tiani, los verbales son tiay 'el asentarse' y tiana 'el assiento"” (1616: 5r).

Finalmente, Santo Tomás explica que "el hombre dize a su hijo o hija (chúri) y la muger les dize (guágua)"; en Huerta encontramos "churi significa 'hijo o hija de varón' y buabua 'hijo o hija de muger”" y en Roxo Mexía, lo siguiente: "De suerte que para dezir 'hijo d'él' se dize ccarichuri y 'hija d'él', huarmichuri. Y para dezir 'hijo d'ella' se dize ccari buabua e 'hija d'ella', huarmi huabua" (1648: 8r). Sancho de Melgar, como vimos en el apartado 3, declina churi 'hijo', pero propone las equivalencias en latín.

El Arte, y vocabolario enla lengva general del Perv atribuido a Blas Valera comienza el capítulo dedicado al nombre distinguiendo entre sustantivos y adjetivos y, entre los ejemplos de estos últimos, propone cinchi 'fuerte' y alli 'bueno'. Después, para explicar la marcación del sexo, propone las construcciones cinchi cari 'varón fuerte', cinchi huarmi 'muger fuerte', vira orco llama 'carnero gordo' y vira china llama 'oveja gorda'. González Holguín también registra el adjetivo cinchi 'fuerte'; en Huerta localizamos tanto alli 'bueno' como çinchi 'fuerte'; y en la Breve instruccion se encuentran sinchi 'cosa fuerte' y sinchi huarmi 'muger fuerte'. Además, Huerta registra llama 'carnero o oveja', ollco llama 'carnero' y china llama 'oveja'; y en Torres Rubio encontramos llamcta 'al carnero'.

La gramática de 1586 distingue el caso vocativo y explica que "el vocativo es semejante al nominativo, aunque algunas vezes le preceden los vocativos de llamar y otras vezes se le posponen, como llamando el hombre a otro hombre dize ya o yau runa, runa-ya o runa yau, 'hola, hombre'” (1586: 2r). Dos de los gramáticos posteriores recogen este ejemplo al tratar del caso vocativo: González Holguín ("El vocativo [...] puede tener $(y a)$ antes o después de sí para cuando llamamos, ya 'hola'", 1607: 1v) y Torres Rubio ("El vocativo tiene $y$ (aunque no siempre) como yayay, 'hola, padre', 1619: 1v). 
A la hora de explicar el plural, en el arte atribuido a Valera se recogen los ejemplos ñaui 'ojos', maqui 'manos' y chaqui 'pies' para defender que en estos casos no es necesario añadir la partícula cuna. Esta misma idea la mantienen Huerta (ñaui 'ojos'), Sancho de Melgar (ñavii 'los ojos', maqui 'las manos') y Torres Rubio (chaqui 'los pies', no diremos chaquicuna). Aguilar es ambiguo a este respecto, pero también recoge el ejemplo citado (ñabui o ñabuicuna 'los ojos', ñabui 'el ojo' y buc ñabui 'un ojo') y González Holguín, que no coincide con Valera en esta cuestión, propone purap ñani 'ambos ojos' o 'entrambos ojos' (o purap ñaniy 'mis dos ojos', purapnin chaquiy 'mis dos pies') frente a ñaui cuna 'los ojos de todos, y no los de uno' y purap o purapnintin maqui o chaqui 'los dos pies o manos'. Al seguir con las explicaciones sobre el uso de la partícula cuna, el autor del Arte, y vocabvlario se percata de que "cuando algún elemento del contexto más próximo indica pluralidad abierta, no es necesario siquiera que aparezca de nuevo el plural. Iskay mayu [dos + río] 'dos ríos'” (Calvo Pérez 1992: 29) y propone yscay buata 'dos años', ejemplo que se recupera en la Breve instruccion ('dos años' iscai huata).

Para explicar la manera en la que se combinan sustantivo y adjetivo en quechua, en el arte de 1586 se alude al ejemplo cinchi runa 'hombre fuerte' y se desarrolla el paradigma de esta construcción como "exemplo delos nombres adjetivados". González Holguín también registra cinchu runa 'el hombre fuerte' y Aguilar declina en el apartado de "nombre cuasiadjetivo" sinchiruna "el hombre fuerte'. Entre los paradigmas que el Arte, y vocabvlario registra al final del capítulo dedicado a los nombres, aparece punchan 'el día' como "exemplo de los nombres acabados en dos vocales". Huerta (punchau 'el día'), Roxo Mexía (ppunchau 'el día'), Aguilar (punchau 'el día') y Sancho de Melgar (ppunchau 'el día') también usan este ejemplo, aunque lo más interesante es que la Breve instruccion desarrolla el paradigma completo de puncha 'el día', tal y como hizo el autor del Arte, y vocabvlario. González Holguín, por su parte, alude a chunca punchao 'diez días' y punchaunintin 'todo un día entero'. Por último, el arte de 1586 desarrolla el paradigma de ángel como 
"exemplo delos nombre acabados en consonante" y Aguilar también lo hace, aunque solo desarrollando el plural angelcuna 'los ángeles'.

Como vimos arriba, González Holguín considera que no es necesario añadir la partícula cuna "cuando el nombre es doblado de su naturaleza” (es el caso de 'ojos', o 'pies') (1607: 2v). A estos ejemplos, añade yscay nin rincriy 'mis dos oídos o orejas' y puraprinri 'ambas orejas'. Este último ejemplo aparece en Huerta (rinri 'orejas') y Sancho de Melgar ("Pero algunas vezes los usa el indio con cuna, como rinc-ricuna 'orejas'”, 1691: 2r). En la gramática de 1607 se usa como ejemplo la voz enemigo (hatun nin aucan 'su mayor enemigo'), que después desarrollarán en un paradigma completo Roxo Mexía (aucca-cuna 'los enemigos') y Aguilar (auca cuna 'los enemigos'). Además, González Holguín registra rurac 'el que haze' y yayaypa 'lo que es de mi padre', construcciones que también aparecen en Huerta. Al mismo tiempo, incluye varios ejemplos con buaccha (ñocanchic buaccha 'nosotros pobres', ñoca buaccha 'yo pobre' y la declinación de Pedro buaccha 'Pedro el que es pobre'), término recogido posteriormente por Huerta ("buacchacuyac significa 'el misericordioso', compónese de buaccha, que significa 'pobre' y de cuyac, que significa 'el que ama', como quien dize 'el que ama al pobre'”, 1616: 6v) y Aguilar (buaccha 'el pobre').

Llama la atención que González Holguín use el antropónimo Pedro en varios ejemplos (Pedrop yayaynpa buanquen 'el tío de Pedro' o Pedro khayna bamucta buacyay 'llama a Pedro el que vino ayer') y este sea recuperado por Huerta (asyachacracmi Pedro Inan manta 'más sabio es Pedro que Juan'), Roxo Mexía (Pedro manmi corccani 'dilo a Pedro') y Aguilar (Pedro man mi corcçani 'dilo a Pedro'). Además, al explicar los llamados "plurales analíticos por vía de repetición” (Calvo Pérez 1993: 350), González Holguín propone los ejemplos hachahacha 'multitud de arboleda' y ttiuttiu 'multitud de arena'. Ambos son recuperados por Sancho de Melgar (sacha, 'el árbol'; sacha sacha 'arboleda o montaña'; ttia 'la arena') y el segundo aparece también en Roxo Mexía (ttiu 'la arena') y Aguilar (ttiu 'la arena'). No obstante, el ejemplo de arena reaparece en los tres casos para dar cuenta de cómo se declinan los nombres acabados en iu. 
González Holguín explica la terminación -ntin, marca del llamado caso colectivo o social (Calvo Pérez 1993, Cerrón Palomino 1987), de la siguiente manera: “Íten para hazer plural de dos parientes relativos entre sí, con nombrar el uno y ponerle plural (ntin) significan a entrambos, como yayantin, el hijo con el padre; coçantin, la muger con su marido" (1607: 9r). Estas mismas estructuras son recuperadas por Huerta (churintin 'hijo y padre'; buarmintin 'muger y marido'), Roxo Mexía (yaya-ntin 'padre y hijo'; ccoçantin 'marido y muger') y Sancho de Melgar (ccozantin 'muger y marido'; yayantin 'hijo y padre'). Finalmente, en el arte de 1607 se registran punchaonintincuna 'todos los días', quillantin cuna 'todos los meses' y buatantincuna 'todos los años', ejemplos que reaparecen en Sancho de Melgar (ppunchauñincua 'todos los días', qquillincuna 'todos los meses' y vvataticuna 'todos los años').

Alonso de Huerta usa el término buccha 'cavellos', que será recuperado por Roxo Mexía (chuccha 'el cabello'), Aguilar (chuccha 'el cabello') y Sancho de Melgar (chuc-cha 'los cabellos'). Por otro lado, en la gramática de 1616 se mencionan las voces puma 'león o leona', ollco puma 'leona' y china puma 'leona', que vuelven a aparecer en Roxo Mexía (orcco-puma 'el león’ y china-puma 'la leona'); además, se registran construcciones con la voz sangre (como yaguarryoc 'el que tiene sangre' o yaguarrmaçiy 'mi allegado en sangre'), término que volverá a aparecer en Torres Rubio (yahuarpa 'de la sangre') y en Sancho de Melgar (yavvar 'la sangre').

Torres Rubio utiliza la expresión caspibuam 'con el palo' a la hora de explicar el caso efectivo y la Breve instruccion comienza sus explicaciones sobre el nombre sustantivo aludiendo a caspi 'el palo'. En la obra de 1619 también aparece varumiruni 'el pedregal y muchas piedras', ejemplo recuperado en Roxo Mexía (rumi-rumi 'pedregal, y no las piedras'), Aguilar (rumirumi 'el pedregal') y Sancho de Melgar (rumi rumi 'pedregal').

Cuando Roxo Mexía explica "el modo de suplir los géneros”, emplea el ejemplo yutthu 'el perdigón o la perdiz' para mostrar cómo se comportan los sustantivos de género epiceno y vuelve a aparecer este ejemplo en la Breve instruccion (yutu 'la perdiz', yutu 
cuna 'las perdices'). Además, como veremos más adelante (tabla 1), la mayoría de los ejemplos propuestos por Roxo Mexía reaparecen en la gramática de Aguilar

Por último, no hemos encontrado ejemplos originales de Aguilar que se filtren en la gramática de Sancho de Melgar ni tampoco ejemplos de este último que aparezcan en la Breve instruccion.

Hasta ahora hemos mostrado los ejemplos que se van repitiendo de gramática en gramática. A partir del recuento de los ejemplos coincidentes y si nos fijamos en los casos en que los ejemplos "cedidos" de una gramática a otra son más de cinco, se vislumbran varias posibles influencias. La gramática de 1586 atribuida a Valera pudo haber dejado su huella en González Holguín, Huerta o en la Breve instruccion; y el arte de González Holguín pudo haber servido de fuente a la gramática de Sancho de Melgar. Ahora bien, estas posibilidades deberán ser confirmadas con un análisis más pormenorizado: sin duda, para poder extraer conclusiones definitivas sobre estas posibles dependencias o descubrir otras nuevas sería necesario analizar un corpus de ejemplos más amplio y compaginar este examen con el estudio de la teoría lingüística presentada por cada gramático, la terminología empleada o la estructuración de los contenidos. Por lo tanto, consideramos que es necesario tomar las coincidencias mostradas arriba con cautela, pues no podemos hacer equivaler en todos los casos la repetición de una voz o de un paradigma a una dependencia entre gramáticas. Téngase en cuenta que muchos de los ejemplos dan cuenta de un léxico común y excepciones a determinadas reglas, o tienen en consideración palabras muy prototípicas. En el caso de Santo Tomás, por ejemplo, el análisis efectuado evidencia que todas las gramáticas posteriores (con la única excepción del arte de 1753) toman ejemplos aparecidos en la primera gramática quechua. Sin embargo, como mantienen Calvo Pérez (2000) o Cerrón Palomino (1995), este texto perdió vigencia una vez publicado el Arte, y vocabolario con el auxilio del Tercer Concilio Limense.

Con todo, hemos encontrado una relación de dependencia que sí resulta significativa: el análisis de los ejemplos contenidos en los capítulos dedicados al nombre evidencia que Aguilar sigue muy de 
cerca a Roxo Mexía, pues, de los 108 ejemplos que hemos vaciado, 68 habían sido registrados con anterioridad por Roxo Mexía; esto quiere decir que el 63\% de los ejemplos de Aguilar que aparecen en el capítulo dedicado al nombre están tomados de Roxo Mexía, un porcentaje nada desdeñable. En la tabla 1 puede consultarse una muestra con algunos de estos ejemplos coincidentes:

\section{Tabla 1. Extracto de ejemplos coincidentes entre Aguilar y Roxo Mexía}

\begin{tabular}{|c|c|}
\hline Aguilar ([1690] 1939: 3-13) & Roxo Mexía (1648: 1r-8v) \\
\hline ccoya 'la reina' [paradigma] & ccoya 'la princesa' [paradigma] \\
\hline yachacocc 'el estudiante' [paradigma] & yachacucc 'el estudiante' [paradigma] \\
\hline auca cuna 'los enemigos' [paradigma] & aucca-cuna 'los enemigos' [paradigma] \\
\hline angel cuna 'los ángeles' [paradigma] & - \\
\hline chuccha o chuccha cuna 'los cabellos' & chuccha o chuccha cuna 'los cabellos' \\
\hline ñahui o ñahui cuna 'los ojos' & - \\
\hline chuccha 'el cabello' & chuccha 'el cabello' \\
\hline ñahui 'el ojo’' & - \\
\hline buc chuccha 'un cabello' & bucc-chuccha 'un cabello' \\
\hline buc ñahui ‘un ojo’ & - \\
\hline $\begin{array}{l}\text { imapaccmi hamurccanqui? ‘'para qué } \\
\text { veniste?' }\end{array}$ & $\begin{array}{l}\text { imapaccmi hamurccanqui? '¿para qué } \\
\text { veniste?' }\end{array}$ \\
\hline micunayacc 'para o a comer' & - \\
\hline $\begin{array}{l}\text { haycapaccmi ratipacunqui? ‘¿por } \\
\text { cuánto o en cuánto vendes?’ }\end{array}$ & $\begin{array}{l}\text { baycapaccmi ratipacunqui? ‘¿por } \\
\text { cuánto vendes?' }\end{array}$ \\
\hline quimça paccmi 'por o en tres' & quimça paccmi 'por tres' \\
\hline tabuapaccmi 'por o en cuatro' & - \\
\hline $\begin{array}{l}\text { hayca ppunchaupaccmi rinqui? ‘¿por } \\
\text { cuántos días vas?' }\end{array}$ & $\begin{array}{l}\text { bayca ppunchaupaccmi rinqui? ‘ ¿por } \\
\text { cuántos días vas?' }\end{array}$ \\
\hline bucchuata paccmi 'por un año' & bucc buata-paccmi 'por un año' \\
\hline $\begin{array}{l}\text { alli runa-paccmi hatalliyqui 'téngote } \\
\text { por hombre bueno' }\end{array}$ & $\begin{array}{l}\text { alli runa-paccmi hatallyqui 'téngote } \\
\text { por hombre bueno' }\end{array}$ \\
\hline $\begin{array}{l}\text { campa buayna capaccmi hatalliyqui } \\
\text { 'téngote por macebo flojo' }\end{array}$ & - \\
\hline
\end{tabular}




\section{A MODO DE CONCLUSIÓN}

Esta primera aproximación al estudio de los ejemplos contenidos en las artes de la lengua quechua compuestas entre 1560 y 1753 ha querido mostrar otras posibilidades de acercamiento a la producción lingüística misionera del área andina. En relación con las hipótesis de partida planteadas, mantenemos que ambas se han cumplido.

En primer lugar, la revisión de la parte ejemplificativa de las gramáticas ha arrojado luz sobre dos aspectos clave que caracterizan la producción misionera. Por una parte, hemos confirmado que la producción lingüística misionera en esta zona es fruto de un trabajo grupal. Se trata de una labor cooperativa entre los misioneros y los indígenas, pues las gramáticas son el resultado de un intenso trabajo de campo: los misioneros se valen de los testimonios orales de los indios para confeccionar sus obras y, así, el uso (frente a la norma) juega un papel decisivo en la elaboración de estos textos. Por otra parte, hemos puesto de relieve la doble dimensión de los ejemplos: por un lado, el ejemplo cumple una serie de funciones relacionadas con la codificación del quechua (ilustrar la regla o la definición propuesta por el misionero, mostrar las excepciones a las reglas, señalar construcciones incorrectas o dar cuenta de la variación lingüística); por otro, la elección de los ejemplos no es azarosa: el ejemplo sirve para que el discente adquiera vocabulario (y con él se acerque a la realidad indígena) y también ayuda a que el aprendiz memorice expresiones útiles para su día a día. Vale la pena recordar que los principales destinatarios de estas gramáticas son los clérigos que no son diestros en quechua; por lo tanto, no es de extrañar que el vocabulario y las frases que ilustran los ejemplos tengan contenido religioso. De esta manera, los autores de las gramáticas están enseñando a otros misioneros cómo transmitir a los indígenas la fe católica, cómo explicar la doctrina en quechua.

Molina Landeros explica que "el discurso religioso aparece recontextualizado, pues es extraído de su espacio natural para ser utilizado en un contexto de enseñanza lingüística” (2016:173). Ahora bien, las gramáticas no solo documentan ejemplos supeditados a la 
religión católica, sino también vocabulario y expresiones útiles para la vida diaria: partes del cuerpo, números, términos de parentesco, animales y expresiones como ando por el camino, voy al pueblo, trae aquella fruta que te di a guardar, téngote por macebo flojo, ya te doy oro, yo te pido plata, ¿de dónde viene?, ¿qué hora es?, ¿por cuántos días vas? I por un año, ¿por qué riñes? / porque eres perezoso... Así pues, los lingüistas misioneros pretenden que sus alumnos dominen las lenguas indígenas, con un doble objetivo: para lograr la evangelización de los indios y para que se desenvuelvan con fluidez en las tareas cotidianas.

En segundo lugar, constatamos que el análisis contrastivo de la parte ejemplificativa de las gramáticas resulta adecuado en el estudio de fuentes e influencias. Ahora bien, consideramos que se trata de un argumento más que debe caminar al lado de otros (la revisión de la doctrina lingüística de las obras, el metalenguaje empleado o la organización de los contenidos, por ejemplo). En este trabajo, el análisis de los ejemplos coincidentes ha revelado que, en los capítulos destinados al nombre, Aguilar copia los ejemplos empleados por Roxo Mexía prácticamente sin excepción y con pocas adiciones propias. Esta conclusión sigue la línea de lo mantenido por Segovia Gordillo (2020b) y, por tanto, podemos sostener que, a la hora de redactar su gramática de la lengua quechua, Aguilar consultó, utilizó y copió la obra de Roxo Mexía. Sin embargo, las dependencias entre Arte, y vocabvlario de 1586 y las gramáticas posteriores, o bien la posible influencia de González Holguín en sus sucesores, no se han visto reflejadas de manera tan clara en el análisis de los ejemplos coincidentes.

\section{REFERENCIAS BIBLIOGRÁFICAS}

Acevedo López, Víctor Felipe y Miguel Ángel Esparza Torres

2020 "Geografía de las lenguas de la lingüística misionera española (XVI-XIX)”. Revista Internacional de Lingüistica Iberoamericana. 18, 36, 15-21. 
Aguilar, Juan de

[1690] 1939 Arte de la lengua Quichua general de indios del Perú. Edición facsimilar de Radamés A. Altieri. Tucumán: Instituto de Antropología.

Alvar Ezquerra, Manuel

2020 Biblioteca Virtual de la Filología Española (BVFE): directorio bibliográfico de gramáticas, diccionarios, obras de ortografía, ortología, prosodia, métrica, diálogos e historia de la lengua.

Consultado: 24 de agosto de 2020. <www.bvfe.es>

Autor Desconocido

1586 Arte, y vocabulario enla lengva general del Perv llamada Quichua, y en la lengua Española. Lima: Antonio Ricardo ${ }^{13}$.

Autor Desconocido

1753 Breve instruccion, o arte para entender la lengua comun de los Indios, segun se babla en la Provincia de Quito. Lima: Imprenta de la Plazuela de San Cristóbal.

Bendezú-Araujo, Raúl

2012 "La terminología de parentesco del quechua en los documentos lingüísticos de los siglos XVI y XVII”. Tesis de Maestría. Pontificia Universidad Católica del Perú. Consultado: 22 de septiembre de 2021. <http://tesis.pucp.edu.pe/repositorio/ handle/20.500.12404/4526>.

Calero Vaquera, María Luisa

2010 "Ideología y discurso lingüístico: la Etnortografía como subdisciplina de la glotopolítica”. Boletín de Filología. 45, 2, 31-48. Consultado:19 de septiembre de 2021. https://doi. org/10.4067/S0718-93032010000200002

Calvo Pérez, Julio

1992 "El plural de las lenguas quechuas”. En Estudios de lingüística amerindia. Actas de las $1^{a}$ Jornadas de Lingüistica Amerindia

13 Hay edición facsimilar de 2009 del original conservado en la Biblioteca Nacional de España de Madrid (BNE R/9166). Estudio de Julio Calvo Pérez, Agencia Española de Cooperación Internacional para el Desarrollo, Madrid. Asimismo, atribuida a Blas Valera, se publicó en 2014 una edición interpretada y modernizada por Rodolfo CerrónPalomino, Raúl Bendezú-Araujo y Jorge Acurio Palma, Pontificia Universidad Católica del Perú-Instituto Riva-Agüero, Lima. 
(Valencia, 6 y 7 de mayo de 1991). Ed., Francisco Raga. Valencia: Universitat de València, 29-52.

Calvo Pérez, Julio

1993 Pragmática y gramática del quechua cuzqueño. Cuzco: Centro de Estudios Regionales Andinos "Bartolomé de las Casas”.

Calvo Pérez, Julio

1997 "La gramática aimara de Bertonio (1603) y la escuela de Juli".

En La descripción de las lenguas amerindias en la época colonial.

Ed., Klaus Zimmermann. Madrid/ Frankfurt: Iberoamericana/ Vervuert, 321-338.

Calvo Pérez, Julio

2000 "Las gramáticas del Siglo de Oro quechua: originalidad y diversidad”. En Las gramáticas misioneras de tradición bispánica (siglos XVI-XVII). Ed., Otto Zwartjes. Amsterdam: Rodopi, 125-201.

Calvo Pérez, Julio

2004 "El Siglo de Oro de la lingüística amerindia: el caso del quechua”. En Dos mundos, dos culturas o de la historia (natural y moral) entre España y Perú. Ed., Fermín del Pino Díaz. Madrid/ Frankfurt: Iberoamericana/ Vervuert, 201-226.

Cancino Cabello, Nataly

2017 “Los paratextos de artes y gramáticas misioneras americanas”. Nueva Revista de Filología Hispánica. 65, 2, 407-440. Consultado: 15 de septiembre de 2021. https://doi.org/10.24201/nrfh. v65i2.3101

CÁrdenas Bunsen, José

2014 "Circuitos del conocimiento: el Arte de la lengua índica de Valera y su inclusión en las polémicas sobre el Sacro Monte de Granada”. Lexis. 38, 1, 71-116. Consultado: 18 de septiembre de $2021<$ https://revistas.pucp.edu.pe/index.php/lexis/article/ view/9850>

Cerrón-Palomino, Rodolfo

1987 Lingüística quechua. Cuzco: Centro de Estudios Rurales Andinos Bartolomé de las Casas. 
Cerrón-Palomino, Rodolfo

1995 "Estudio introductorio". En Grammatica o arte de la lengua general de los indios de los reynos del Peru. Cuzco: Centro de Estudios Regionales Andinos Bartolomé de las Casas, viILXVII.

Cerrón-Palomino, Rodolfo

2010 "El contacto inicial quechua-castellano: la conquista del Perú con dos palabras”. Lexis. 34, 2, 369-381. Consultado: 4 de septiembre de 2021. <http://revistas.pucp.edu.pe/index.php/ lexis/article/view/1545>.

Charta, Red Internacional

2013 Criterios de edición de documentos bispánicos (orígenes-siglo xix). Consultado: 24 de agosto de 2020. <https://www.redcharta.es/criterios-de-edicion/>.

Chevillard, Jean-Luc, Bernard Colombat, Jean-Marie Fournier, JeanPatrick Guillaume y Jean Lallot

2007 "L'exemple dans quelques traditions grammaticales (formes, fonctionnement, types)". Langages. 166, 2, 5-31. Consultado: 5 de septiembre de 2021. https://doi.org/10.3917/lang.166.0005

ChiERICHETTI, Luisa

2010 "Los ejemplos en algunos métodos de español para italianos (siglos XIX-XX)". En Dai maestri di lingue ai professori di lingue in Europa [8]: atti delle giornate di studio "Les 'langues entre elles' dans les contextes et situations d'enseignement en Europe, du XVIe siècle au début du XXe siècle: médiations, circulations, comparaisons». Ed., Javier Villoria. Granada: Comares, 109-125. Consultado: 21 de septiembre de 2021. $<$ http://amsacta.unibo.it/5609/1/10_Chierichetti.pdf>.

Cuevas Alonso, Miguel

2011 "Las ideas lingüísticas en las gramáticas misionero-coloniales de Filipinas (siglos XVII y XVIII)”. Tesis doctoral. Universidad de Vigo.

Dedenbach-Salazar Sáenz, Sabine

2008 "Dictionaries, Vocabularies, and Grammars of Andean Indigenous Languages". En Guide to documentary sources for Andean studies: 1530-1900. Ed., Joanne Pillsbury. Norman: University of Oklahoma Press, 235-264. 
Escudero Paniagua, Francisco

2019

“¿Cómo se ilustró la teoría? Los ejemplos en la investigación de la sintaxis (XVIII-XIX)”. En Historiografía de la reflexión sintáctica: metaanálisis y estudios en torno al español. Ed. y Coord., Alfonso Zamorano Aguilar. Eds., Adela GonzálezFernández, Sergio Rodríguez-Tapia y Juan Miguel González Jiménez. München: Lincom, 197-223.

Esparza Torres, Miguel Ángel

2005 "Los prólogos de Alonso Molina (c. 1514-1585): destrucción de una ideología”. Península: Revista de Estudios Ibéricos. 2, 69-92. Consultado: 4 de septiembre de 2021. <https://ler. letras.up.pt/uploads/ficheiros/2958.pdf>.

EsParza Torres, Miguel Ángel

2015 "On the Linguistic Ideas Underlying the Work of 16thCentury Mesoamerican Missionaries". Historiographia Lingüística. 42, 2/3, 211-232. Consultado: 14 de septiembre de 2021. https://doi.org/10.1075/hl.42.2-3.01esp

Esparza Torres, Miguel Ángel

2017 "Las ideas lingüísticas en los orígenes de la lingüística misionera en Mesoamérica: enunciados, argumentos, imágenes y ejemplos”. Rilce. Revista de Filología Hispánica. 33, 1, 135-64. Consultado: 8 de septiembre de 2021 https://doi. org/10.15581/008.33.1.135-64

Esteba Ramos, Diana

2006 "La ejemplificación en las gramáticas del castellano del siglo XVII: modelos y léxico”. En El castellano y su codificación gramatical II. De 1614 (B. Jiménez Patón) a 1697 (F. Sobrino). Dir., José Jesús Gómez Asencio. Burgos: Instituto Castellano y Leonés de la Lengua, 685-698.

Ezcurra Rivero, Álvaro y Raúl Bendezú-Araujo

2017 "Gramáticas y vocabularios coloniales del quechua y del aimara (1560-1619)”. En Historia de las literaturas en el Perú. Vol. 1. Literaturas orales y primeros textos coloniales. Coords., José Carlos Godenzzi y Carlos Garatea. Lima: Biblioteca Nacional del Perú, 123-162. 
González Holguín, Diego

1607 Grammatica y arte nveva dela lengva general de todo el Peru, llamada lengua Qquichua, o lengua del Inca. Lima: Francisco del Canto.

HERNÁNDEZ, Esther

2013 "Aspectos metodológicos de la lingüística misionera hispánica”. En El mundo indígena desde la perspectiva actual. Ed., Pilar Máynez. México: Grupo Destiempos (Dossiers), 223247.

Hovdhaugen, Even

1996 "Missionary Grammars - An Attempt at Defining a Fiel of Research". En ... and the Word was God: missionary linguistics and missionary grammar. Ed., Even Hovdhaugen. Münster: Nodus Publikationen, 9-22.

Huerta, Alonso de

1616 Arte dela lengra quechua general delos Yndios de este Reyno del Piru. Lima: Francisco del Canto.

LLITERAS, Margarita

2001 "Sobre la formación del corpus de autoridades en la gramática española”. En History of Linguistics in Spain: Historia de la lingüística en España. Eds., E. F. Konrad Koerner y HansJosef Niederehe. Amsterdam: John Benjamins. II, 215-228. Consultado: 23 de agosto de 2021. https://doi.org/10.1075/ sihols.100.15lli

Lliteras, Margarita y Santiago García-Jalón

2006 "Alcance del hebraísmo renacentista en la demostración contrastiva de propiedades gramaticales”. En Studia Lingüística et Philologica in Memoriam Feliciano Delgado (1926-2004). Eds., María Luisa Calero Vaquera, Francisco Osuna García y Alfonso Zamorano Aguilar. Córdoba: Universidad de Córdoba, 35-54.

MANNHeim, Bruce

1991 The language of the Inka since the European invasion. Austin: University of Texas Press. 
Mannheim, Bruce

2002 "Gramática colonial, contexto religioso". En Incas e indios cristianos. Élites indígenas e identidades cristianas en los Andes coloniales. Ed., Jean-Jacques Decoster. Cusco: CBC; Kuraka; IFEA, 209-220. Consultado: 16 de agosto de 2021. <https:// books.openedition.org/ifea/4092?lang=es $>$.

Marchello-Nizia, Christiane y Geneviève Petiot

1977 "Les exemples dans le discours grammatical”. Langages. 45, 84-111. Consultado: 6 de agosto de 2021. https://doi. org/10.3406/lgge.1977.1939

Molina Landeros, Rosío del Carmen

2016 Gramáticas jesuíticas del Noroeste novohispano (siglos XVIIXVIII). Mexicali: Universidad Autónoma de Baja California.

Nebrija, Elio Antonio de

[hacia 1488] Introduciones latinas contrapuesto el romance al latín (c. 1488). 1996 Edición de Miguel Ángel Esparza y Vicente Calvo. Münster: Nodus.

Niederehe, Hans-Josef

1994 "Los ejemplos de la 'Gramática de la lengua castellana' de Elio Antonio de Nebrija”. Nebrija V centenario: Actas del Congreso Internacional de Historiografía Lingüística. Eds., Ricardo Escavy, José Miguel Hernández Terrés y Antonio Roldán. Murcia: Universidad de Murcia.1, 413-424.

Quijada van den Berghe, Carmen

2011 "Autoridades y canon en gramáticas del español del siglo XVIII”. En El castellano su codificación gramatical. De 1700 a 1835. Coord., José Jesús Gómez Asencio. Burgos: Instituto Castellano y Leonés de la Lengua, 805-831.

Regúnaga, María Alejandra y Otto Zwartjes

2020 "La lingüística misionera a la luz de sus congresos: retrospectiva y avances”. Revista argentina de historiografía lingüística. XII, 1, 1-10.

Ridruejo, Emilio

2014 "Constantes y variables en la Lingüística Misionera hispánica”. En Métodos y resultados actuales en Historiografía Lingüistica. Eds., María Luisa Calero, Alfonso Zamorano Aguilar, 
Francisco Javier Perea Siller, M. ${ }^{a}$ del Carmen García Manga y María Martínez-Atieza. Münster: Nodus Publikationen, 617641.

RODRÍGUEZ-AlcalÁ, Carolina

2007 "L’exemple dans les grammaires jésuitiques du guaraní”. Histoire Épistémologie Langage. 166, 112-126. Consultado: 18 de septiembre de 2021. https://doi.org/10.3917/lang.166.0112

Rodríguez-Alcalá, Carolina y José Horta Nunes

2008 "Langues amérindiennes à la Renaissance: norme et exemples dans les descriptions du tupi et du guaraní”. Histoire Épistémologie Langage. 30, 2, 25-70. Consultado: 18 de septiembre de 2021. https://doi.org/10.3406/hel.2008.3166

Roxo Mexía y Ocón, Juan

$1648 \quad$ Arte de la lengva general de los indios del Perv. Lima: Jorge López de Herrera.

SANCho de Melgar, Esteban

1691 Arte de la lengva general del ynga llamada Qquechbua. Lima: Diego de Lira.

SANTO Tomás, Domingo de

1560 Grammatica o arte de la lengua general de los Indios de los Reynos del Peru. Valladolid: Francisco Fernández de Córdoba $^{14}$.

Segovia Gordillo, Ana

2016 "Repercusiones de la escuela de Juli en los trabajos lingüísticos de González Holguín y Bertonio”. Revista argentina de bistoriografía lingüistica. VIII, 2, 123-154.

Segovia Gordillo, Ana

2020a "Las gramáticas misioneras sobre la lengua quechua a través de sus paratextos". Nueva Revista de Filología Hispánica. 68, 2, 451-497. Consultado: 18 de julio de 2021. https://doi. org/10.24201/nrfh.v68i2.3645

14 Hay edición facsimilar de 1994 a cargo de Rodolfo Cerrón-Palomino, Cultura Hispánica-Agencia Española de Cooperación Internacional para el Desarrollo, Madrid. 
Segovia Gordillo, Ana

$2020 \mathrm{~b} \quad$ "Interjecciones y conjunciones en las artes de la lengua quechua: continuidades y rupturas". Revista Internacional de Lingüística Iberoamericana. XVIII, 36, 235-256.

Torres Rubio, Diego de

1619 Arte de la lengva quichua. Lima: Francisco Lasso.

Zamorano Aguilar, Alfonso

2013 "Relaciones entre pensamiento pedagógico y teoría gramatical en España durante el primer tercio del siglo XX”. RILCE: Revista de Filología Hispánica. 29, 2, 514-544. Consultado: 18 de septiembre de $2021<$ https://revistas.unav.edu/index.php/ rilce/article/view/2957>.

ZimmermanN, Klaus

2004 "La construcción del objeto de la historiografía lingüística misionera”. En Missionary Linguistics/ Lingüistica misionera. Selected Papers from the First International Conference on Missionary Linguistics (Oslo, 13-16 March 2003). Eds., Otto Zwartjes y Even Hovdhaugen. Amsterdam/ Philadelphia: John Benjamins, 8-32. Consultado: 10 de septiembre de 2021. https://doi.org/10.1075/sihols.106.03zim

ZwarTJES, Otto (ed.)

2000 Las gramáticas misioneras de tradición hispánica (siglos XVIXVII). Amsterdam: Rodopi.

Zwartjes, Otto

2007 “Los 'romances' en las gramáticas andinas de la tradición misionera española”. En La Romania en interacción: entre historia, contacto y politica. Ensayos en homenaje a Klaus Zimmermann. Eds., Martina Schrader-Kniffki y Laura Morgenthaler García. Madrid/ Frankfurt, Iberoamericana/ Vervuert, 817-835.

Zwartjes, Otto

2012 "The historiography of missionary linguistics: Present state and further research opportunities". Historiographia Linguistica. 39, 2/3, 185-242. Consultado: 7 de septiembre de 2021. https://doi.org/10.1075/hl.39.2-3.01zwa 
Zwartjes, Otto y Cristina Altman (eds.)

2005 Missionary linguistics II/ Lingüistica Misionera II: orthography and phonology. Selected papers from the Second International Conference on Missionary Linguistics (Sao Paulo, 10-13 march 2004). Amsterdam/ Philadelphia: John Benjamins. Consultado: 7 de septiembre de 2021. https://doi.org/10.1075/sihols.109

Zwartjes, Otto, Gregory James y Emilio Ridruejo (eds.)

2007 Missionary linguistics III/ Lingüistica Misionera III: morphology and syntax. Selected papers from the Third and Fourth International Conferences on Missionary Linguistics (Hong Kong/Macau, 12-15 march 2005, Valladolid, 8-11 March 2006). Amsterdam/ Philadelphia: John Benjamins. Consultado: 7 de septiembre de 2021. https://doi.org/10.1075/sihols.111

Zwartjes, Otto, Klaus Zimmermann y Martina Schrader-KniffKi (eds.)

2014 Missionary linguistics V/ Lingüistica Misionera V: Translation theories and practices. Selected papers from the Seventh International Conference on Missionary Linguistics (Bremen, 28 February - 2 March 2012). Amsterdam/Philadelphia: John Benjamins. Consultado: 7 de septiembre de 2021. https://doi. org/10.1075/sihols.122

Zwartjes, Otto, Ramón Arzápalo Marín y Thomas C. Smith-Stark (eds.)

2009 Missionary linguistics IV/ Lingüistica misionera IV: lexicography. Selected papers from the fifth International Conference on Missionary Linguistics (Mérida, Yucatán, 1417 March 2007). Amsterdam/ Philadelphia: John Benjamins. Consultado: 7 de septiembre de 2021. https://doi.org/10.1075/ sihols.114

Recepción: 25/08/2020

Aceptación: 01/06/2021 